\title{
Characterization of an Aggregated Three-Dimensional Cell Culture Model by Multimodal Mass Spectrometry Imaging
}

Lucy E. Flint, Gregory Hamm, Joseph D. Ready, Stephanie Ling, Catherine J. Duckett, Neil A. Cross, Laura M. Cole, David P. Smith, Richard J. A. Goodwin, and Malcolm R. Clench*

Cite This: Anal. Chem. 2020, 92, 12538-12547

Read Online

ACCESS

Llll Metrics \& More

Article Recommendations

Supporting Information

ABSTRACT: Mass spectrometry imaging (MSI) is an established analytical tool capable of defining and understanding complex tissues by determining the spatial distribution of biological molecules. Threedimensional (3D) cell culture models mimic the pathophysiological environment of in vivo tumors and are rapidly emerging as a valuable research tool. Here, multimodal MSI techniques were employed to characterize a novel aggregated 3D lung adenocarcinoma model, developed by the group to mimic the in vivo tissue. Regions of tumor heterogeneity and the hypoxic microenvironment were observed based on the spatial distribution of a variety of endogenous molecules. Desorption electrospray ionization (DESI)-MSI defined regions of a hypoxic core and a proliferative outer layer from

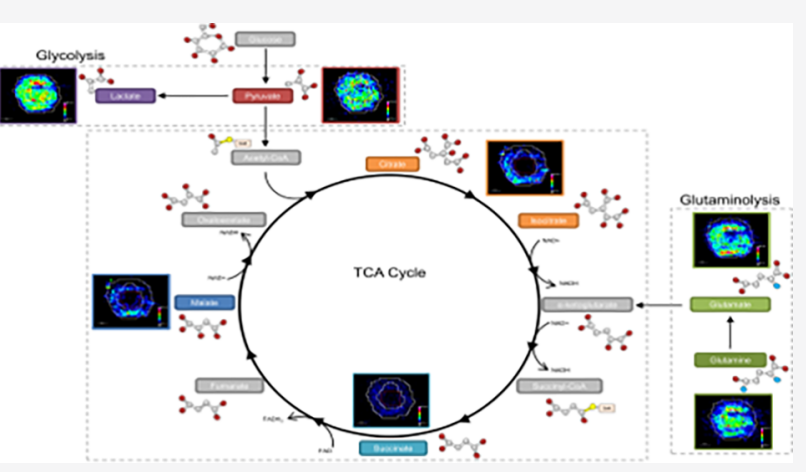
metabolite distribution. Targeted metabolites (e.g., lactate, glutamine, and citrate) were mapped to pathways of glycolysis and the TCA cycle demonstrating tumor metabolic behavior. The first application of imaging mass cytometry (IMC) with 3D cell culture enabled single-cell phenotyping at $1 \mu \mathrm{m}$ spatial resolution. Protein markers of proliferation $\left(K_{\mathrm{i}}-67\right)$ and hypoxia (glucose transporter 1 ) defined metabolic signaling in the aggregoid model, which complemented the metabolite data. Laser ablation inductively coupled plasma (LA-ICP)-MSI analysis localized endogenous elements including magnesium and copper, further differentiating the hypoxia gradient and validating the protein expression. Obtaining a large amount of molecular information on a complementary nature enabled an in-depth understanding of the biological processes within the novel tumor model. Combining powerful imaging techniques to characterize the aggregated 3D culture highlighted a future methodology with potential applications in cancer research and drug development.

M ass spectrometry imaging (MSI) is a sophisticated technology capable of simultaneously mapping a variety of molecules within a biological sample. The benefits of conventional MSI techniques compared to other imaging modalities are the abilities to detect ionizable compounds in both targeted and untargeted methods without the use of specific labeling reagents. ${ }^{1}$ The spatial localization of a molecule can determine the interplay of biological functions and interactions within a tissue. This also enables a greater biological understanding of cellular phenotypes and their structural organization, in addition to the surrounding microenvironment. MSI has therefore had a major influence on cancer research and drug development by utilizing spatial localization of biomarkers, therapeutics, their active metabolites, and cellular responses. ${ }^{1}$

Depending on the biological sample and the molecules of interest, different MSI techniques can be employed for optimum analysis. Matrix-assisted laser desorption/ionization (MALDI) is the most widely used MSI technique across many applications due to its high spatial resolution and speed of acquisition. MALDI-MSI can detect a wide range of analytes in an untargeted manner including metabolites, lipids, peptides, and proteins. ${ }^{2-4}$ Desorption electrospray ionization (DESI)MSI is also widely used due to the minimal sample preparation requirement of this ambient ionization methodology. ${ }^{5}$ The combination of DESI with Orbitrap and QTOF type mass spectrometers has generated images with high mass specificity for metabolites and small molecule therapeutics in tissue samples. ${ }^{6,7}$ The requirement for the study of trace elements or metal isotope distribution in tissues has also seen the development of laser ablation-inductively coupled plasma (LA-ICP)-MSI, ${ }^{8,9}$ a technique that has been applied to the analysis of metal-containing therapeutics such as cisplatin. ${ }^{10,11}$ Advancements of LA-ICP-MSI have evolved to imaging mass cytometry (IMC), a novel multiplex method capable of tissue phenotyping, and imaging biological processes at a high spatial

Received: June 4, 2020

Accepted: July 29, 2020

Published: July 29, 2020 
resolution $(<1 \mu \mathrm{m})$. Detection of proteins is achieved in this technique using metal-labeled antibodies specific to proteins and protein modifications. IMC has demonstrated highdimensional single-cell analysis capabilities on numerous tissue types $^{12,13}$ and directly visualized platinum-based therapeutics and the biological responses to treatment. ${ }^{14}$ Recent studies have demonstrated the benefits of the use of multimodal MSI for the same study for the extraction of complementary molecular information to enable a wider detection of a diverse range of analytes within corresponding samples. ${ }^{15,16}$

Parallel to the developments in MSI, aspects of preclinical therapeutic research are exploring more sustainable and cheaper biological models than the use of in vivo models. Three-dimensional (3D) cell cultures offer a biologically relevant model that can be used for early stage drug development and screening studies. ${ }^{17,18}$ The cellular complexity of $3 \mathrm{D}$ models mimics the biological microenvironment of tissues in a way that $2 \mathrm{D}$ cultures cannot. Due to recent societal issues regarding the use of animal models in science, the demand for 3D cultures has grown significantly. They offer a way in which the 3 Rs principle, i.e., the reduction, replacement, and refinement of the use of animals in scientific research can be implemented in preclinical studies. ${ }^{19}$ Tumor spheroids are among the most common biological systems developed. These cellular spheres mirror the tumor microenvironment of proliferative, hypoxic, and necrotic regions through gradients of oxygen and nutrients. By recapitulating the cell-cell interactions and the growth and differentiation processes of tumors, spheroids are a valuable research tool to study realistic drug behavior.

Over the past decade, advancements in technology, especially the achievable spatial resolution, have enabled the analysis of tumor spheroids by MSI. Li and Hummon ${ }^{20}$ were the first to establish the combination of MALDI-MSI with spheroids for the characterization of protein distributions in a HCT116 colon carcinoma model. Proteins including Histone $\mathrm{H} 4$ and cytochrome $\mathrm{c}$ were localized across the spheroid, and a specific, unidentified peak $(m / z 12828)$ was localized within the necrotic core. More recently, Tucker et al. ${ }^{21}$ employed high spectral resolution Fourier transform-ion cyclotron resonance (FT-ICR) MALDI-MSI to determine metabolite distributions in MCF-7 breast cancer spheroids. The group mapped metabolites associated with hypoxia through biochemical processes including glycolysis and the hexosamine biosynthetic pathway. By improving the understanding of cellular functions in tumor spheroids, MSI techniques give opportunities to unravel a drug's absorption, distribution, and metabolism. The Hummon group have reported numerous drug toxicity applications with MALDI-MSI, investigating the distribution of small molecule chemotherapeutics, ${ }^{22,23}$ combinational drugs, $^{24}$ and immunotherapy ${ }^{25}$ in colon carcinoma spheroid cultures.

Recently, literature has debated whether tumor spheroids fully recapitulate the heterogeneous nature of an in vivo tumor. ${ }^{26}$ This is due to methods in which they are cultured. Multicellular tumor spheroids (MCTS) are the most common model formed by aggregation, rather than proliferation, via ultralow attachment techniques. Their homogeneity negatively impacts true biological behavior and therefore limits drug efficacy experiments. To overcome this limitation, our group has developed a novel $3 \mathrm{D}$ model which is formed via the aggregation of clonal spheroids. ${ }^{27}$ This $3 \mathrm{D}$ model, termed an "aggregoid" is cultured by isolating and aggregating tumor spheres generated from an alginate bead culture. Similar to the spheroid model, the aggregoid displays a gradient of oxygen and nutrients, whereby a depletion in the core produces a hypoxic environment. This gradient was observed by fluorescently staining the aggregoid culture, identifying a viable outer region and a necrotic core (Supplementary Figure 1). The asymmetric nature of the aggregoid model produces a heterogeneous tissue and therefore allows for a more morphological representation of an in vivo tumor. The aggregoid model can also be cultured to an approximate diameter of $1 \mathrm{~mm}$, which is large enough for in-depth spatial distribution studies. MALDI-MSI analysis of this aggregoid model was demonstrated by Palubeckaite et al. ${ }^{27}$ for the determination of drug and endogenous metabolite distributions. Metabolites were localized in regions corresponding to the hypoxic gradient, including $\mathrm{m} / \mathrm{z} 426.1$ within the core, and $m / z 281.3$ located within the outer areas of an SAOS-2 osteosarcoma aggregoid. MALDI-MSI analysis was also employed to detect doxorubicin, a major chemotherapeutic, within the core of the SAOS-2 aggregoid and for mapping the metabolic responses to the treatment.

In this study, we have characterized a novel aggregoid tumor model created from HCC827 lung adenocarcinoma cells using multiple MSI modalities: DESI-MSI, IMC, and LA-ICP-MSI. We show how the aggregoid model displays similar phenotypical characteristics to tumor spheroid cultures, demonstrating its potential as an in vitro research tool. Additionally, we have identified specific molecular markers that define regions of hypoxia and key biological processes by the analysis of metabolites, proteins and protein modifications, and elemental compounds by their respective imaging platforms.

\section{METHODS}

3D Culture Growth. Epithelial HCC827 lung adenocarcinoma cell line (ATCC) was cultured in Dulbecco's modified Eagle's medium (DMEM) (Lonza Ltd., U.K.), supplemented with $10 \%$ fetal bovine serum (FBS) and $1 \%$ penicillinstreptomycin (Lonza Ltd., U.K.). Aggregoids were generated based on the method of Palubeckaite et al., ${ }^{27}$ as follows: Cells were maintained at $37{ }^{\circ} \mathrm{C}, 5 \% \mathrm{CO}_{2}$ and grown to $80 \%$ confluence prior to use. To generate the initial tumor spheres, cells were suspended in $1.2 \%(\mathrm{w} / \mathrm{v})$ alginic acid (SigmaAldrich, U.K.) in $0.15 \mathrm{M} \mathrm{NaCl}$ at $1 \times 10^{6}$ cells $/ \mathrm{mL}$ and extruded out of a needle into $0.2 \mathrm{M} \mathrm{CaCl}_{2}$ to polymerize the alginate into beads. Beads were washed with $0.15 \mathrm{M} \mathrm{NaCl}$ before culturing in DMEM media for 14 days to yield spheroids $\sim 100 \mu \mathrm{m}$ in diameter, and media was replaced every $72 \mathrm{~h}$. Alginate beads were dissolved in an alginate buffer (55 $\mathrm{mM}$ sodium citrate, $30 \mathrm{mM}$ EDTA, $0.15 \mathrm{M} \mathrm{NaCl}$ ) to release spheroids into solution. Spheroids were washed with PBS (Lonza, Castleford, U.K.) before seeding spheroids into $1 \%$ agarose-coated 96-well plate in growth medium. Spheroids were cultured for 7 days to form aggregoids of an approximate $1 \mathrm{~mm}$ diameter before harvesting. Spheroid and aggregoid development were analyzed by fluorescent staining with Hoechst 33342 and propidium iodide staining $(10 \mu \mathrm{g} / \mathrm{mL}$ each) for $30 \mathrm{~min}$. Fluorescent images were obtained using the Olympus IX81 Microscope (Southend-on-Sea, U.K.) and images were captured using $\mathrm{Cell}^{\wedge} \mathrm{F}$ Multifluorescence and Imaging Software (Europa Science Ltd., Cambridge, U.K.) (Supplementary Figure 1). 
Tissue Preparation. Aggregoids were prepared for imaging analysis based on the tissue embedding protocol. Briefly, aggregoids were washed in PBS prior to embedding in media made of $7.5 \%$ hydroxypropyl-methylcellulose (HPMC) and $2.5 \%$ polyvinylpyrrolidone (PVP). Embedded tissues were flash frozen in liquid nitrogen and stored at $-80{ }^{\circ} \mathrm{C}$. Frozen aggregoids were sectioned at $10 \mu \mathrm{m}$ thickness using a Leica CM3050 cryostat (Leica Microsystems, U.K.) operating at $-18{ }^{\circ} \mathrm{C}$. Sections were thaw-mounted onto polylysine glass slides followed by immediate desiccation with $\mathrm{N}_{2}$ and subsequent vacuum packing for storage at $-80{ }^{\circ} \mathrm{C} .{ }^{28}$

DESI-MSI. Small molecule imaging was performed using a Q-Exactive mass spectrometer (Thermo Fisher Scientific Inc., Germany) operated in negative mode. The mass spectrometer was equipped with a custom-built automated DESI ion source. The mass resolution was set to 70000 , and mass spectra were collected in the mass range $m / z 80-900$ at a spatial resolution $30 \mu \mathrm{m}$. The electrospray solvent was $\mathrm{MeOH} /$ water $(95: 5 \mathrm{v} / \mathrm{v}$ ) set at a flow rate of $1 \mu \mathrm{L} / \mathrm{min}$ with nebulizing nitrogen used as gas at pressure of 2 bar. Imaging analysis was performed by combining individual horizontal line scans and converting into imzML format using the imzML converter V.1.1.4.5 (www. maldi-msi.org). The images were analyzed by SCiLS Lab MVS Premium 3D Version 2020a (Bruker Daltonics, Germany) employing root-mean-square (RMS) normalization.

Discriminatory Analysis. The aggregoid DESI-MSI data file was segregated into regional clusters by spatial segmentation processing by which the "core" and "outer" regions were identified (SCiLS, Bruker Daltonics). Discrimination between the two regions was achieved by automatically finding $m / z$ values by employing the receiver operating characteristic (ROC) tool to calculate the area under the curve (AUC) value (Supplementary Table 1). The raw data file from the DESI-MSI was uploaded to METASPACE (https:// metaspace2020.eu/) for metabolite identification of the discriminated $m / z$ values by employing the Human Metabolome Database (HMDB) (tolerance $<1 \mathrm{ppm}$ ). Metabolic pathways were assigned based on the KEGG database by importing identified $m / z$ values into Pathos software (http:// motif.gla.ac.uk/Pathos/). The ion abundances for the $m / z$ values were generated into histograms for comparison between regions using GraphPad Prism software (La Jolla, CA).

IMC Staining. Tissues were fixed with $4 \%$ paraformaldehyde for $10 \mathrm{~min}$ at room temperature (RT). Prior to staining, tissues were permeabilized with $1 \times$ casein solution containing $0.1 \%$ Triton $\mathrm{X}-100$ for $5 \mathrm{~min}$ at RT. Tissues were then incubated with blocking buffer ( $1 \times$ casein solution) for $30 \mathrm{~min}$ at RT. An antibody cocktail was made containing the appropriate dilutions for the antibodies. Tissues were incubated with the antibody cocktail overnight at $4{ }^{\circ} \mathrm{C}$. DNA Ir-Intercalator (Fluidigm) was diluted 1:400 and applied to tissues for $30 \mathrm{~min}$ at RT. Washes with PBS were performed three times between each step, with the last step washed in deionized water for $30 \mathrm{~s}$. Slides were left to air-dry until analysis.

IMC Analysis. Images were acquired using the Hyperion Imaging System (Fluidigm), rasterizing at $200 \mathrm{~Hz}$ and with the laser tuned to fully ablate the tissue without etching the glass. TIFF files of each acquisition were then exported for analysis in the HALO image analysis platform (Indica Laboratories). Using a random forest machine learning Tissue Classifier module, each image was segmented into the background and inner, core, and outer areas of each aggregoid. Using the
Hiplex module, the DNA intercalator was used to first segment the nucleus of each cell, and a proxy for the cytoplasm of each cell defined in a $1 \mu \mathrm{m}$ radius from the nucleus, before thresholds set to define positive cell staining for each marker. Percentage positivity of each cell was then defined within the inner and outer region of the aggregoid.

LA-ICP-MS Analysis. Experiments were conducted using a NexION 350X ICPMS (PerkinElmer) coupled to an UP-213 LA system (New Wave Research) with a frequency quintupled $213 \mathrm{~nm} \mathrm{Nd}$ : YAG laser. Laser parameters were optimized to a $6 \mu \mathrm{m}$ spot size with laser power $46 \%, 25 \mu \mathrm{m} / \mathrm{s}$ scan speed, 0.07 $\mathrm{J} \mathrm{cm}^{-2}$ laser fluence, and $20 \mathrm{~Hz}$ repetition rate. The sample was ablated line by line with $6 \mu \mathrm{m}$ raster spacing at $1.31 \mathrm{~min}$ acquisition time. For the ICP-MS instrument there was a direct flow with a rate of $1.4 \mathrm{~L} / \mathrm{min}$. The following settings were used in standard mode with an $18 \mathrm{~L} / \mathrm{min}$ plasma gas flow, $1.2 \mathrm{~L} /$ min auxiliary gas flow at $1600 \mathrm{~W}$ RF power. Isotopes monitored included ${ }^{24} \mathrm{Mg},{ }^{66} \mathrm{Zn}$, and ${ }^{63} \mathrm{Cu}$, and the instrument was controlled using Syngistix software. Data analysis was achieved using Iolite Software on Igor Pro (WaveMetrics, USA).

Histological Staining. After DESI-MSI, aggregoid sections were stained using Mayer's hematoxylin and eosin solutions. Sections were fixed in $4 \%$ paraformaldehyde for $10 \mathrm{~min}$ before staining with hematoxylin for $1 \mathrm{~min}$. Tissues were rinsed in tap water before and after submerging in acid alcohol. Tissues were subsequently stained with eosin for $30 \mathrm{~s}$ prior to washing tap water, then subsequently washed 3 times with absolute ethanol for $1 \mathrm{~min}$. Finally, tissues were submerged in xylene substitute for $1 \mathrm{~min}$ twice and mounted using DPX mountant. Stained tissues were imaged with an Aperio CS2 digital pathology scanner (Aperio Tech., Oxford, U.K.) at 40X and visualized with ImageScope software (Aperio Tech.).

\section{RESULTS AND DISCUSSION}

Metabolite Imaging. One major hallmark of cancer is an altered cellular metabolism to generate a sufficient energy source contributing to the initiation, growth, and maintenance of tumors. ${ }^{29}$ During tumor growth, a hypoxic microenvironment is developed due to the gradient of oxygen and nutrients. In the present study, the metabolic profile within the lung adenocarcinoma aggregoid model was investigated by employing a DESI Thermo Q-Exactive MSI to classify regions of a hypoxic core and a proliferative outer area. Initial processing of the aggregoid images was conducted to spatially segment the data. This is a process whereby the image is segregated into regions; pixels within proximity that share similar spectral characteristics are grouped together into a segment. These segments are then classified into regions which represent phenotypical features of a tissue. The aggregoid data was segmented into three main regions that depicted a gradient-like phenotype: a core, an annular zone, and an outer region (Figure 1b,c). From the 2- and 3-dimensional images, the clear discrimination of the regional clusters corresponded to the histology stain of the same section after MSI analysis (Figure 1a). From this, the spectra from each region were extracted to distinguish the distributions of key metabolites within the aggregoid. For the purpose of separating metabolites to distinct regions, the core and the outer zones were the main focus when observing the distribution of species, as the intermediate region was anticipated to be nondiscriminatory.

Within the aggregoid model, key metabolites involved in cancer metabolism were identified with a mass error of $<0.5$ 

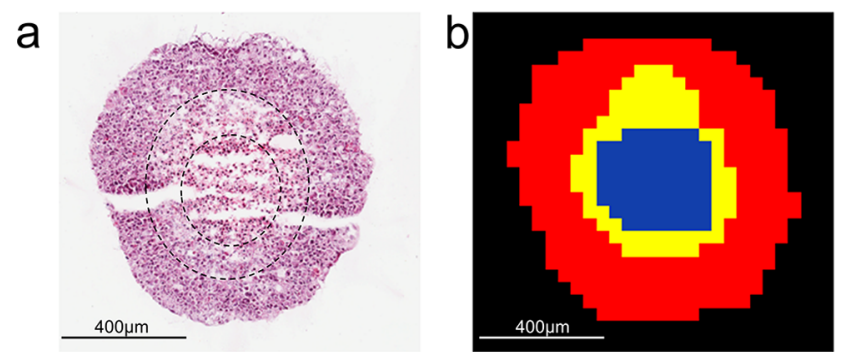

C

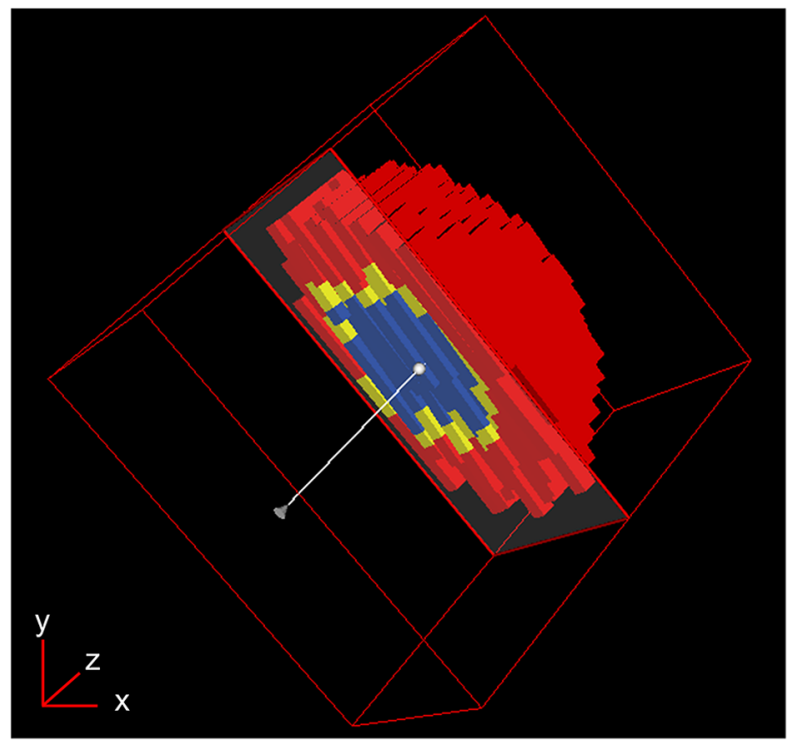

Figure 1. Spatial segmentation of HCC827 aggregoid model from metabolite data by DESI-MSI. (a) H\&E stain of central aggregoid section showing three separate regions within the tissue. Slight fissures can be observed in the tissue which formed during sectioning. Scale bar $400 \mu \mathrm{m}$. (b) Spatial segmentation of central aggregoid section identified three clustering regions that correspond to the hypoxia gradient: necrotic core (blue), annular quiescent region (yellow), and proliferative outer region (red). Scale bar $400 \mu \mathrm{m}$. (c) Realigned 3D construct of aggregoid displaying segmentation pattern throughout the model.

ppm (Supplementary Table 1). A major metabolic substrate that is regulated by the tumor microenvironment is lactate. Within the aggregoid, a high intensity of lactate $(\mathrm{m} / \mathrm{z}$ 89.02440) was distributed throughout indicating the presence of metabolic activity (Figure $2 \mathrm{~b}$ ). An increase in the expression of lactate converted from glucose via the glycolysis reaction is thought to be the predominant pathway to promote tumor survival and growth rather than following oxidative metabolism, otherwise known as the Warburg effect. ${ }^{30}$ An elevated expression of lactate in the core of the aggregoid also implies the presence of hypoxia. In anaerobic conditions, the rate of glycolysis increases due to insufficient oxygen levels to promote tumor survival. A similar distribution of a glycolysis intermediate, pyruvate $(\mathrm{m} / z$ 87.00880) was also observed (Figure 2a). The localization of pyruvate across the aggregoid, with elevated levels in the core validates the assumption of an increased rate of glycolysis in response to hypoxia. A key molecule associated with increased lactate production is the expression of hypoxia-inducible factor alpha (HIF-1 $\alpha$ ), which is stabilized in a hypoxic environment due to the lack of oxygen and therefore a direct marker of hypoxia. HIF- $1 \alpha$ is responsible for regulating the expression of numerous genes under hypoxic conditions. Specifically, HIF- $1 \alpha$ promotes the transportation of glucose into the cell by increasing the expression of the glucose transporter 1 (Glut1). ${ }^{31}$ Additionally, HIF- $1 \alpha$ promotes a high glycolysis rate by inducing both pyruvate dehydrogenase kinase (PDK) and lactate dehydrogenase A ( $\mathrm{LDH}-\mathrm{A})$ to prevent the metabolism of pyruvate into acetyl-CoA to feed the tricarboxylic acid (TCA) cycle and rather by favoring the conversion of lactate. ${ }^{32,33}$

The image analysis identified an increased distribution of glutamine $(\mathrm{m} / \mathrm{z} 145.06190)$ within the core of the aggregoid (Figure 2c). Glutamine is considered a major bioenergetic substrate that sources the TCA cycle by its metabolism to the intermediate $\alpha$-ketoglutarate achieved by the anaplerotic pathway, glutaminolysis. ${ }^{34}$ The TCA cycle is described as the epicenter of cell metabolism due to the extensive supply of metabolic substrates that are utilized for energy production. ${ }^{35}$ The localization of glutamine within the core suggests the cells within the hypoxic environment are substituting for the lack of pyruvate sourcing the TCA cycle. Interestingly, glutamate $(\mathrm{m} /$ $z$ 146.04590), an intermediate of glutaminolysis, is distributed toward the outer region of the aggregoid (Figure $2 \mathrm{~d}$ ). The TCA cycle is heavily utilized by proliferating cells for growth, the suppression of glutamine conversion to glutamate in the core therefore implies the presence of necrosis. Several spheroid studies have reported that the increase in diameter decreases the cell viability due to the reduced levels of oxygen and nutrients, thus the spheroid eventually develops an inner necrotic core. ${ }^{36,37}$ By examining the gene expression profiles, Daster et al. ${ }^{38}$ reported the development of a necrotic region in multicellular spheroids larger than $500 \mu \mathrm{m}$. Since the diameter of the aggregoid model is approximately $1 \mathrm{~mm}$, the presence of an inner necrotic core is highly likely. Fluorescent staining of the aggregoid with propidium iodide validates this necrotic region (Supplementary Figure 1) and additionally shows the large asymmetric hypoxic area opposed to the simple radial gradient in a typical spheroid model, which could explain the asymmetric metabolite distribution in Figure $2 \mathrm{a}-\mathrm{d}$. In contrast, the distributions of the major TCA cycle intermediates citrate $(\mathrm{m} / z 191.01980)$, malate $(\mathrm{m} / z$ $133.01430)$, and succinate $(\mathrm{m} / z 117.01940)$ were observed with more annular features within the outer proliferative region of the aggregoid (Figure $2 \mathrm{e}-\mathrm{g}$ ), implying a surplus of oxygen and nutrients surrounding the aggregoid and the absence of cell proliferation in the core. By identifying the significant metabolites that drive cancer metabolism, it was possible to map the ion density images onto their corresponding pathways to associate the metabolic activity with specific regions of the aggregoid (Figure 3).

Proliferating cancer cells utilize fatty acids as they have essential roles as structural components of the membrane matrix, secondary messengers for signaling pathways, and sources for energy production. ${ }^{39}$ Here fatty acid distribution was imaged within the aggregoid by DESI-MSI and identified with a mass error $\leq 0.7 \mathrm{ppm}$ (Supplementary Table 1 ). The image analysis demonstrated the presence of two polyunsaturated fatty acids, FA (18:2), e.g., linoleic acid at $\mathrm{m} / \mathrm{z}$ 279.23280, and FA (20:4), e.g., arachidonic acid at $\mathrm{m} / z$ 303.23300, within the proliferative region (Figure 4a,b). The metabolite glutathione (GSH) $(\mathrm{m} / z$ 306.07650) displayed a similar localization to the fatty acids described with elevated levels surrounding the hotspot within the outer region (Figure 4c). GSH protects cells against reactive oxygen species (ROS), a normal product from cellular metabolism, through the oxidation of its sulfhydryl group to form glutathione disulfide 

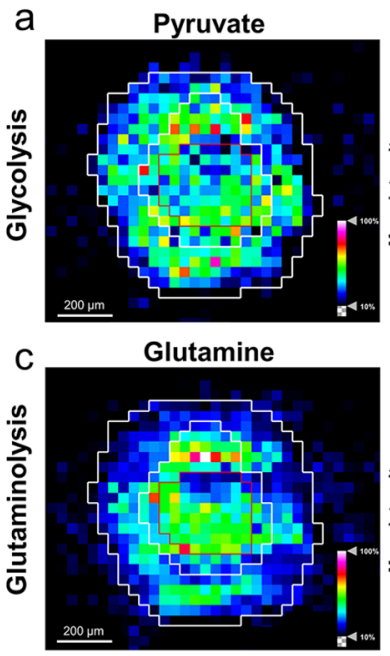

Citrate
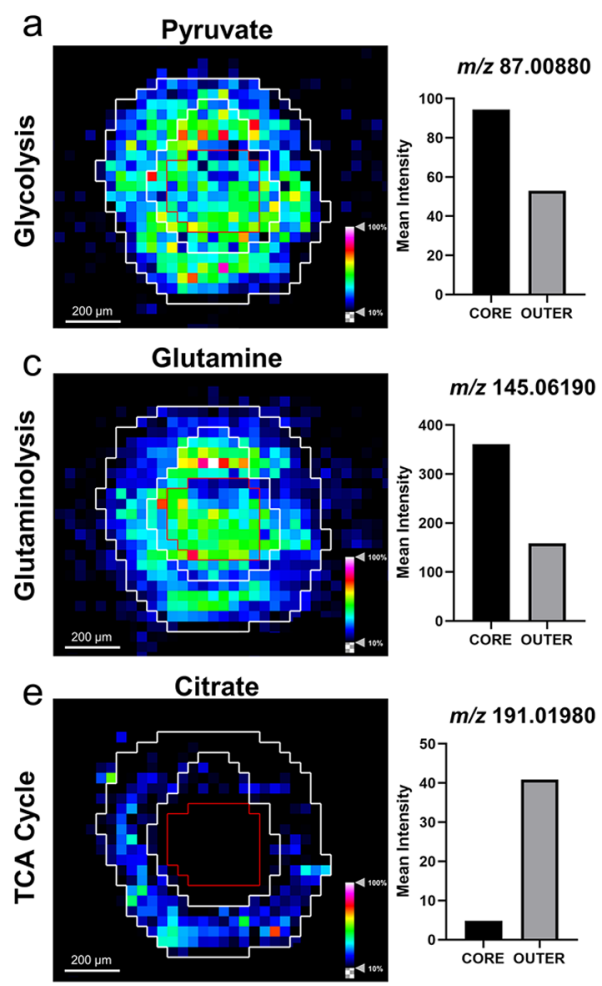

b
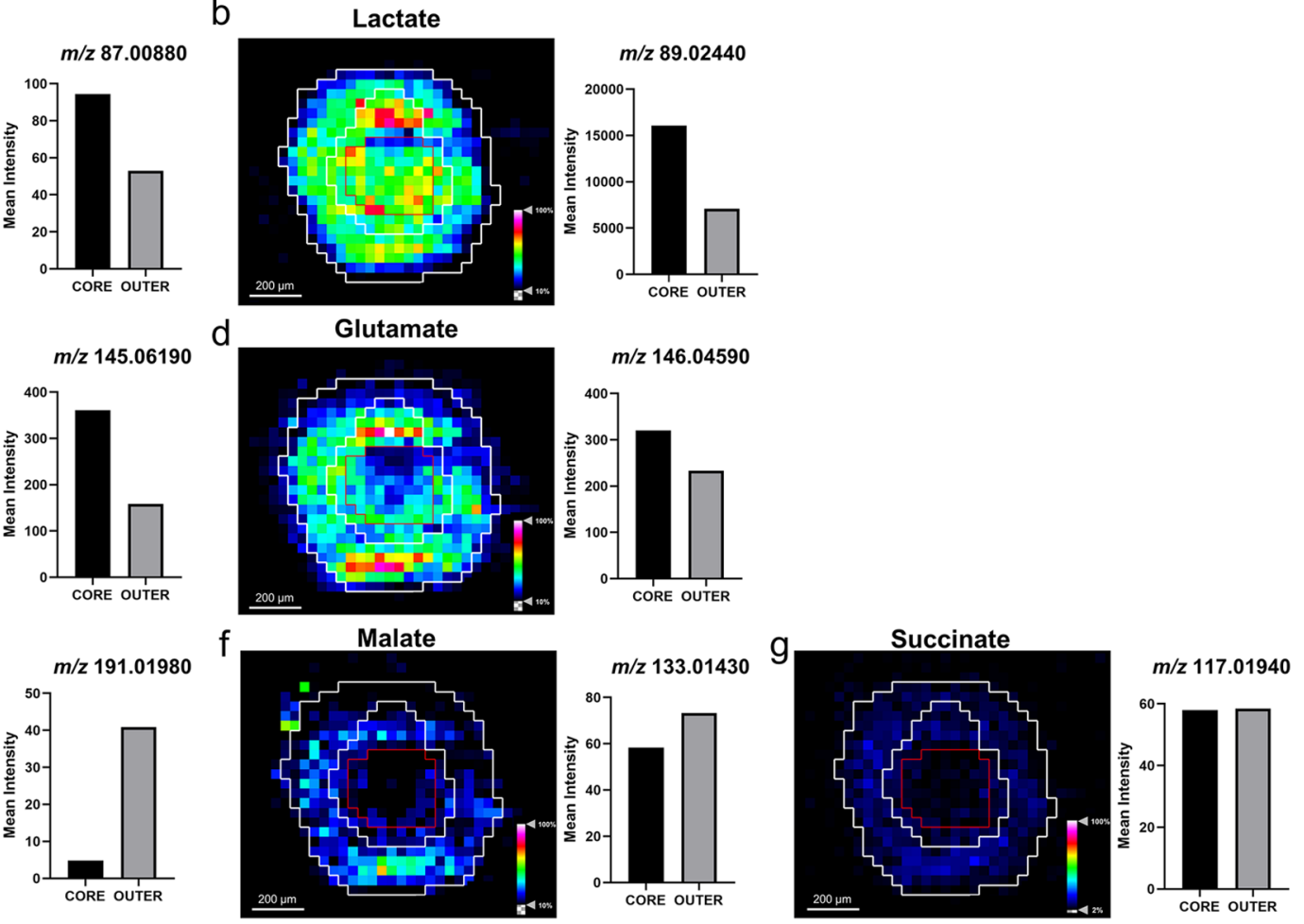

Figure 2. Distribution of metabolites regulating cancer growth and survival within the HCC 827 aggregoid central section by DESI-MSI. Ion density maps of metabolites outlining the core and the outer area on the image. Mean intensity plotted on bar graph against the core and outer regions. Scale bar $200 \mu \mathrm{m}$. Intermediates of the glycolysis reaction: (a) pyruvate, $\mathrm{m} / z 87.00880$ and (b) lactate, $m / z$ 89.02440. Glutaminolysis reaction: (c) glutamine, $\mathrm{m} / z 145.06190$ and (d) glutamate, $\mathrm{m} / z$ 146.04590. TCA cycle: (e) citrate, $\mathrm{m} / z$ 191.01980; (f) malate, $\mathrm{m} / z$ 133.01430; and $(\mathrm{g})$ succinate, $m / z 117.01940$.

(GSSG)..$^{40}$ The colocalization of GSH with the fatty acids suggests an area of high metabolic activity. Interestingly, there was a lack of GSH in the core of the aggregoid, which is heavily associated with oxidative stress (Figure 4c). In hypoxia, the expression of antioxidant genes including GSH metabolic genes are induced to allow cells to regulate ROS. However, it has been shown that in the presence of excess ROS, GSH is depleted which leads to the activation of apoptosis. ${ }^{41}$ The presence of GSH (or the lack of) can therefore be a potential measure of oxidative stress within the aggregoid model. The importance of defining heterogeneity within the in vitro aggregoid model allows a further understanding of a realistic tumor microenvironment and the true metabolic behavior of an in vivo cancer. This information can then be utilized in applications of drug development.

Single-Cell Tumor Characterization. IMC is a novel, multiplex imaging platform capable of high-dimensional tissue phenotyping and the detection of signaling activities by the analysis of protein and protein modification markers at singlecell resolution $(1 \mu \mathrm{m})$. The analysis of proteins within tissues can define essential cellular functions such as proliferation, metabolism, gene expression, organization, and apoptosis. ${ }^{42}$ Modifications to such proteins can manipulate their spatial distribution, composition, and their function, ${ }^{43}$ which can contribute to tumor progression. In the present study, IMC was employed for single-cell phenotyping of the HCC 827 aggregoid model for an in-depth characterization of the tumor microenvironment. Proteomic markers relevant to lung adenocarcinoma were selected to identify key components of cellular organizations, functions, and signaling.
Due to the complex heterogeneity of cancer tissues, morphological and structural components provide a navigational aid to determine the initial tissue organization. ${ }^{13}$ In this study, such cellular elements included DNA and epithelial tumor markers. The DNA intercalator selected was a generic marker, selected to identify the size and shape of the nucleus in individual cells within the aggregoid (Figure 5a). This data was used to spatially segment the image to calculate the percentage positive cells for each marker (HALO, Indica Laboratories) (Supplementary Figure 3).

Tumor markers observed within the HCC827 aggregoid were epithelial cadherin (E-cadherin) and pan-cytokeratin (Pan-CK). The image analysis of both markers identified similar distributions with elevated expression levels within the outer proliferative region of the aggregoid (Figure 5b,c). In epithelial cells, E-cadherin and cytokeratin are responsible for mediating cell-cell adhesion and mechanical support via intermediate filaments, respectively. The absence of these markers within the core is possibly due to the breakdown of cell interactions as a result of necrosis. Simiantonaki et al. ${ }^{44}$ reported a similar correlation with cellular necrosis and a lack of E-cadherin distribution in the core of HT-29 colorectal carcinoma spheroids via immunohistochemistry. Interestingly, the expression of both E-cadherin and cytokeratin can determine epithelial-mesenchymal transition (EMT), a process which promotes tumor progression and metastasis. In EMT, both epithelial markers are either downregulated or lost coupled with a gain of mesenchymal markers, N-cadherin and vimentin. ${ }^{45}$ Studies have demonstrated that EMT signaling can be induced by HIF- $1 \alpha$ in tumor spheroids. ${ }^{46,47}$ Without analyzing markers of the mesenchymal phenotype, this process 


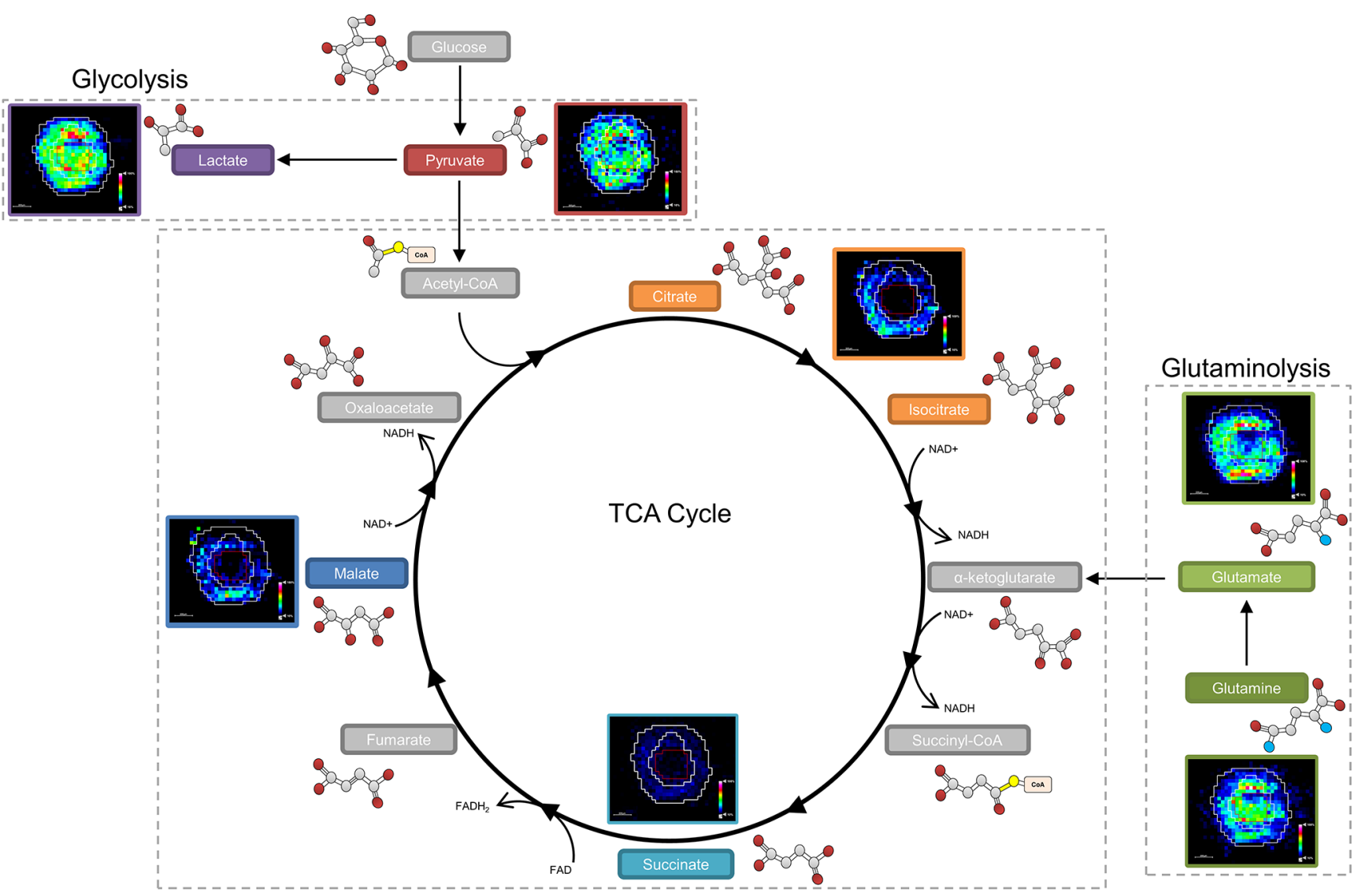

Figure 3. Mapping metabolites to biological pathways defined areas of tumor metabolism. The glycolysis reaction is highly expressed across the whole aggregoid section demonstrating the Warburg effect. Conversion of glutamine to glutamate is showing reduced expression in the core. The TCA intermediates present within the proliferative outer region. Metabolite images obtained by DESI-MSI analysis. Intermediates acetyl-CoA, $\alpha$ ketoglutarate, succinyl-CoA, fumarate, and oxaloacetate were not observed.

cannot be confirmed. However, as necrosis and EMT have a crucial part in tumor progression, future aggregoid analysis with IMC has potential for applications in drug development and resistance.

Alternatively, Tenascin C (TNC) is an extracellular matrix (ECM) marker considered an active component of cancer. Relatively high expression of the marker was localized within the necrotic core of the aggregoid (Figure 5d). TNC is thought to promote survival and invasion by regulating the expression of proangiogenic factors such as vascular endothelial growth factor (VEGF) modulated by HIF- $1 \alpha{ }^{48}$ Additionally, TNC has been associated with inducing EMT changes with the downregulation of E-cadherin. ${ }^{49}$ Thus, the TNC marker correlates with the distribution of the E-cadherin marker (Figure 6b).

To distinguish regions of the tumor microenvironment and to complement the findings from the metabolite distributions, specific markers of proliferation and hypoxia were included. $K_{\mathrm{i}^{-}}$ 67 is a cellular marker, present in all stages of the cell cycle except for early G1 and G0 quiescent phases. The high expression of $K_{\mathrm{i}}-67$ present within the outer region of the aggregoid therefore implies an active proliferative zone (Figure 5e). In addition, phosphorylated Histone $\mathrm{H} 3$ ( $\mathrm{pHH} 3$ ) marker was identified in only a few specific cells, yet still located primarily in the outer region of the aggregoid (Figure 5f). $\mathrm{HH} 3$ is a nuclear core protein, and when phosphorylated at serine10 , is specifically involved in mitotic chromatin condensation. ${ }^{50}$ Hence, the expression of $\mathrm{pHH} 3$ can identify cells undergoing mitosis. It can be concluded that the cells within the outer region of the aggregoid are highly proliferative implying a nonhypoxic area compared to the cells within the core, thus tightly corresponding to the distributions of the TCA cycle intermediates from the DESI-MSI analysis.

On the other hand, Glut1 (glucose transporter 1) is a proxy hypoxia marker. Elevated levels of the marker were observed within the necrotic core of the aggregoid (Figure $5 \mathrm{~g}$ ). Glut1 is a hypoxia responsive gene, which is upregulated by HIF-1 $\alpha$ to maintain an adequate energy supply in response to reduced oxidative phosphorylation. ${ }^{51}$ High levels of Glut1 complement the high lactate expression from the metabolite analysis, implying an increase in glucose transport into cells for lactate production via glycolysis. From the overlay image analysis, an inverse distribution of $K_{\mathrm{i}}-67$ and Glutl can distinguish the two major regions of the tumor microenvironment: proliferative outer and hypoxic core (Figure 6c). Phosphorylated S6 ribosomal protein ( $\mathrm{pS6}$ ), an active marker for mTOR signaling for growth and metabolism, is also regulated by hypoxia. In contrast, the expression of pS6 was observed primarily within the outer region of the aggregoid, with high levels within specific cells (Figure $5 \mathrm{~h}$ ). In hypoxic conditions, the activity of the mTOR pathway is reduced, negatively impacting on the pS6 expression. ${ }^{52}$ Both Glut1 and pS6 markers therefore identified metabolic signaling within the aggregoid that is affected by hypoxia.

Alternatively, phosphorylated Histone $\mathrm{H} 2 \mathrm{AX}(\gamma \mathrm{H} 2 \mathrm{AX})$ is a marker for DNA damage and stress and can be indicative of 
a

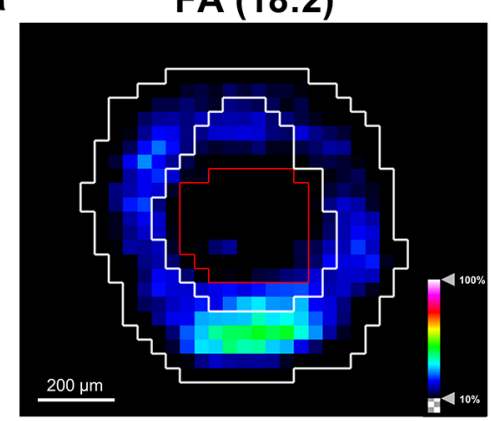

b
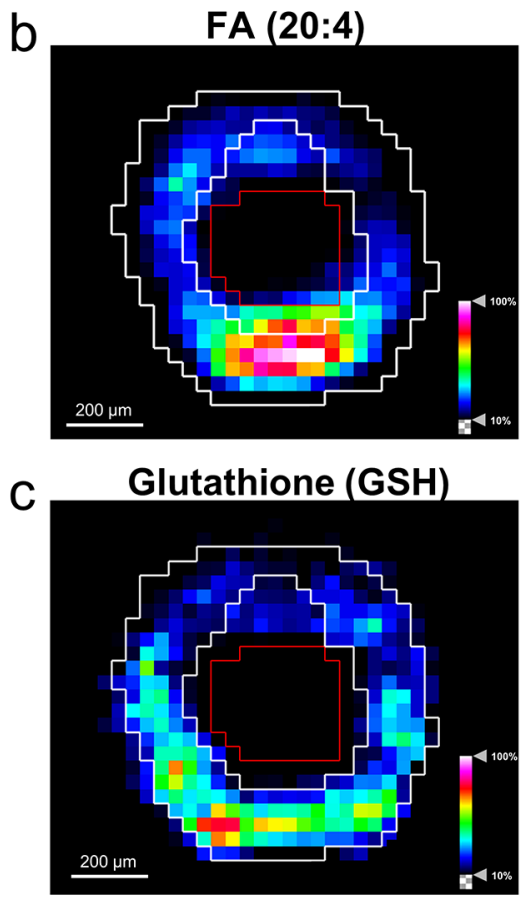

$m / z 279.23280$

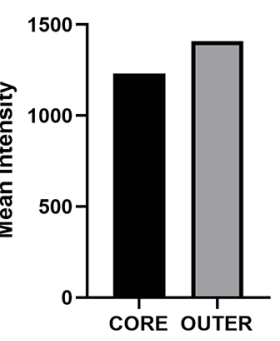

$m / z 303.23300$

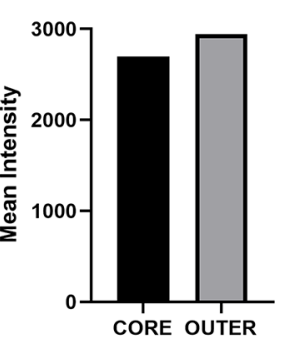

$m / z 306.07650$

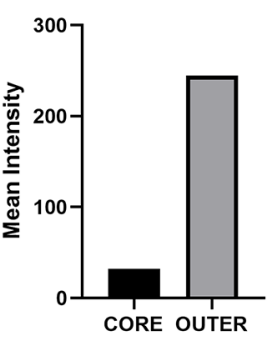

Figure 4. Fatty acid species observed in proliferative outer region by DESI-MSI. Ion density maps of metabolites outlining the core and the outer area on the image. Mean intensity plotted on bar graph against the core and outer regions. Scale bar $200 \mu \mathrm{m}$. (a) FA (18:2), $m / z$ 279.23280; (b) FA (20:4), $m / z$ 303.23300; (c) GSH, $m / z 306.07650$.

cellular apoptosis. ${ }^{53}$ This therefore explains the accumulation of $\gamma \mathrm{H} 2 \mathrm{AX}$ within the hypoxic core of the aggregoid (Figure 5i). From the image analysis, however, high expression levels of $\gamma \mathrm{H} 2 \mathrm{AX}$ was also observed within the proliferative outer region (Figure 5i). Due to oxidative stress, induced by natural ROS from metabolic activity, proliferative cells are subjected to constant DNA damage. ${ }^{54}$ Therefore, the distribution of $\gamma \mathrm{H} 2 \mathrm{AX}$ throughout the aggregoid is supported. In the future, $\gamma \mathrm{H} 2 \mathrm{AX}$ marker has potential to be used for the detection of cellular stress within the aggregoid, with elevated levels when subject to therapeutic treatment.

This is the first report on the analysis of 3D cell culture models with IMC. The usage of IMC to characterize the HCC827 aggregoid model based on morphological and structural markers specific for an epithelial tumor, growth and proliferation, and the hypoxia gradient of the tumor microenvironment has been demonstrated (Figure 6d). Furthermore, with the single-cellular resolution capabilities of IMC, it was possible to distinguish individual cells and the matrix surrounding based on the cellular localization of such

protein markers. Therefore, IMC demonstrates promise for high-dimensional phenotyping of 3D cell culture models at a greater spatial resolution than is currently possible with the other MSI modalities employed in this study.

Endogenous Elemental Analysis. Deficiencies, defects, and accumulation of metal compounds within cells are known to be a hallmark of cancer and disease. Within tissues, metals have a heterogeneous distribution whereby high concentrations can be associated with high metabolic activity. ${ }^{9}$ Therefore, visualizing the metal composition within a tissue can provide essential information to understanding their key functions in different environments, such as hypoxia or nutrient rich areas. The composition of abundant metal isotopes ${ }^{24} \mathrm{Mg}$, ${ }^{66} \mathrm{Zn}$, and ${ }^{63} \mathrm{Cu}$ were selected to analyze within the HCC827 aggregoid model. To measure the abundance of low mass range metal ions at high sensitivity, LA-ICP-MSI was employed.

In the cell, $\mathrm{Mg}$ and $\mathrm{Zn}$ are essential components to drive cell growth, division, and proliferation. ${ }^{55,56}$ Observations from the LA-ICP-MSI analysis localized both elements of high expression solely within the outer proliferative region of the aggregoid (Figure $7 \mathrm{~b}, \mathrm{c}$ ). Similar to $\mathrm{K}_{\mathrm{i}}-67, \mathrm{Mg}$ plays a key role in the cell cycle except for early G1 and G0 quiescent phases. ${ }^{57}$ Thus, the absence of $\mathrm{Mg}$ is indicative of a nonproliferative region or necrotic core. $\mathrm{Zn}$, on the other hand, has been directly linked to the degradation of HIF- $1 \alpha$ under normoxic conditions. ${ }^{58}$ Under hypoxic conditions, however, this process is downregulated to enable stabilization of HIF- $1 \alpha$. It is therefore possible that the absence of $\mathrm{Zn}$ within the aggregoid core is associated with the activation of HIF-1 $\alpha$ in hypoxia; whereby $\mathrm{Zn}$ is possibly exported to the proliferative zone where high levels are required for metabolic activity.

In contrast, the $\mathrm{Cu}$ levels in the aggregoid were elevated within the necrotic core (Figure $7 \mathrm{~d}$ ). Increasing evidence has linked $\mathrm{Cu}$ with HIF-1 $\alpha$ via the hypoxia signaling pathway as a response to oxidative stress to regulate $\mathrm{Cu}$-dependent genes. $^{59,60}$ These include BNIP3, a cell death factor that induces necrosis, ${ }^{61}$ and VEGF, which stimulates angiogenesis. ${ }^{62}$ Both are stimulating factors in hypoxia. In agreement with this, VEGF is also known to be regulated by TNC, which from the IMC analysis was also localized within the core of the aggregoid (Figure 5d). In addition, HIF-1 $\alpha$ accordingly promotes the upregulation of the $\mathrm{Cu}$-efflux transporter, ATP7A, ${ }^{63}$ which tightly regulates levels of free $\mathrm{Cu}$ ions to prevent the formation of ROS. Thus, elevated $\mathrm{Cu}$ concentrations could imply an active export of free $\mathrm{Cu}$ ions into the ECM, accumulating in a less dense area of the aggregoid. As necrotic cells are unregulated, the core therefore becomes the source of metabolic debris.

At present, there is only a limited amount of literature on the study of endogenous elemental compounds in 3D cultures by LA-ICP-MSI. Yet the analysis of tumor spheroids with this technique has had some interest regarding the localization of platinum-based therapeutics and hypoxia-responsive drugs. ${ }^{10,64}$ Theiner et al. ${ }^{11}$ differentiated morphological characteristics of a necrotic core, quiescent zone, and proliferative outer region through the analysis of platinum accumulation within HCT116 colon cancer spheroids. However, the elemental compositions in this study are consistent with literature reported in studies employing X-ray fluorescence microscopy (XFM), an alternative analytical technique capable of elemental analysis at high sensitivity. Zhang et al. ${ }^{65}$ reported similar distributions of $\mathrm{Zn}$ and $\mathrm{Cu}$ within DLD-1 colon carcinoma spheroids implying the 
a

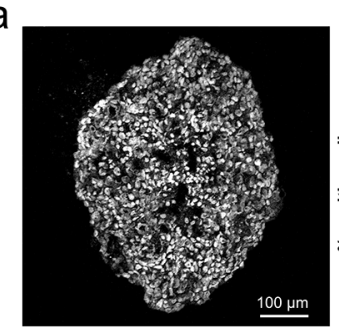

d

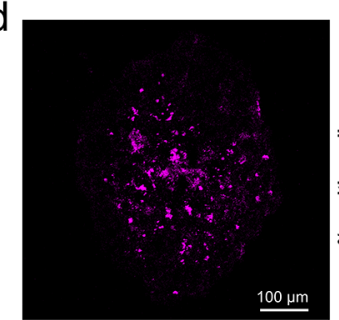

g

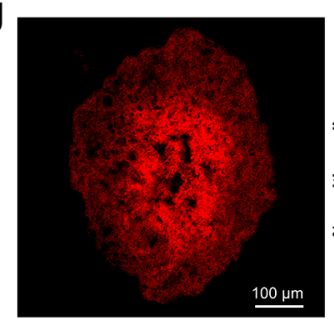

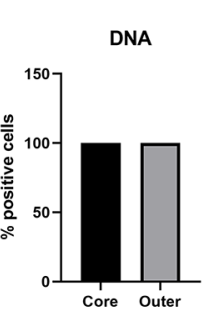
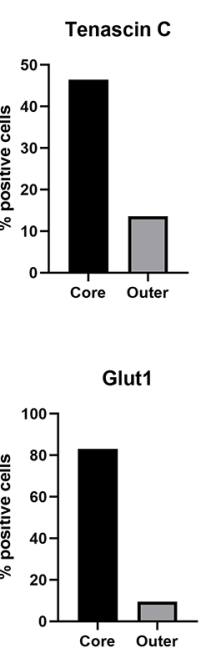

b

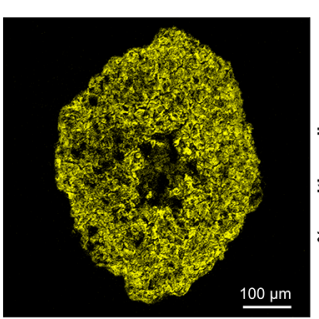

e

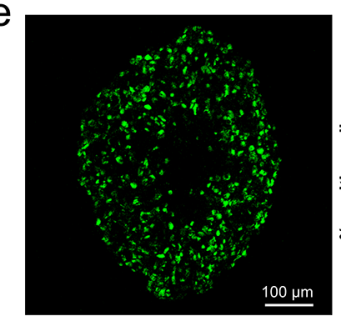

$\mathrm{h}$

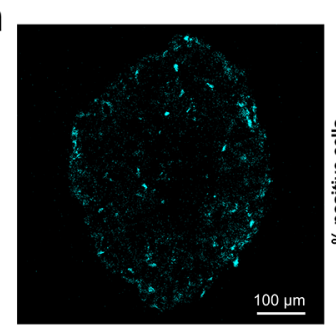

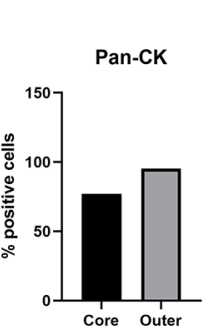
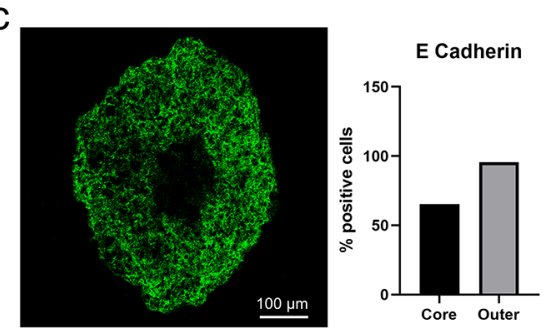

f
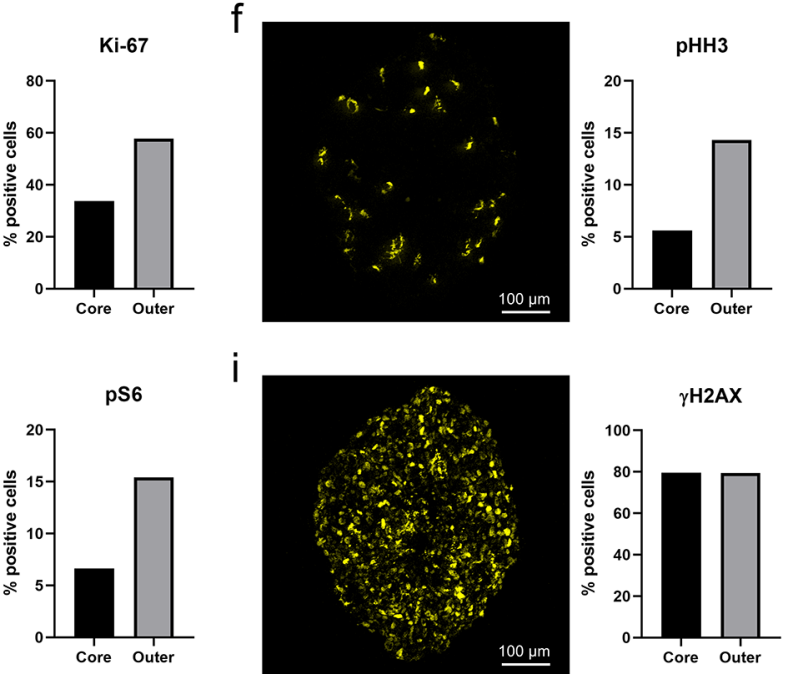

Figure 5. Representative IMC images of biological processes at subcellular detail in the HCC827 aggregoid model. Scale bar, $100 \mu \mathrm{m}$. Percentage positive cells plotted on bar graph against the core and outer regions. (a) DNA intercalator identified individual cells within the aggregoid section. Epithelial tumor markers: (b) Pan-CK, (c) E-Cadherin, and (d) Tenascin C (TNC). Proliferation markers: (e) $K_{\mathrm{i}}-67$ and (f) pHH3. Hypoxia influenced markers: $(\mathrm{g}) \mathrm{pHH} 3$ and $(\mathrm{h}) \mathrm{pS} 6$. DNA damage marker: (i) $\gamma \mathrm{H} 2 \mathrm{AX}$.
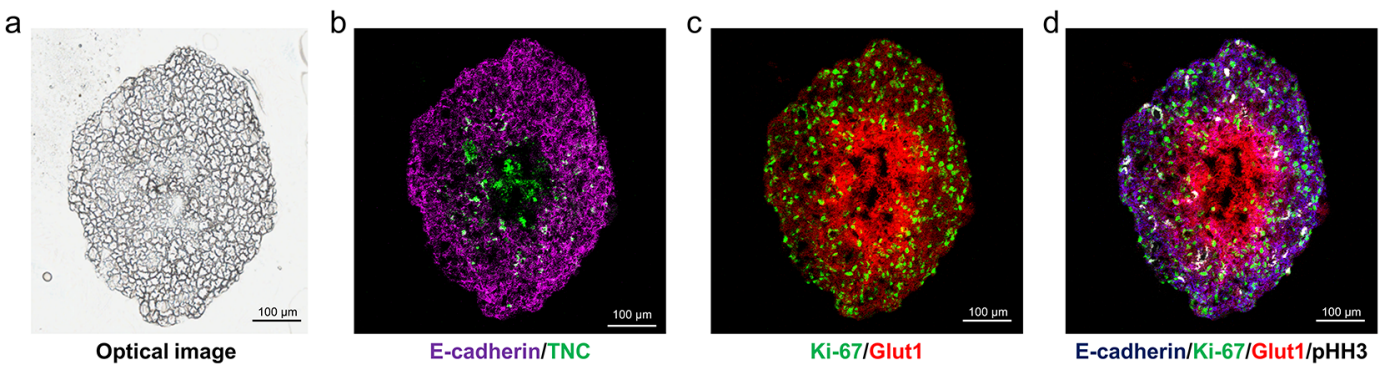

E-cadherin/Ki-67/Glut1/pHH3

Figure 6. Structural organization of biological processes for in-depth phenotyping of HCC827 aggregoid model by IMC. (a) Optical image of aggregoid prior to staining with antibodies and image analysis. Scale bar, $200 \mu \mathrm{m}$. Overlay of IMC markers displays representative images of (b) epithelial tumor markers: Ecadherin, TNC; (c) proliferation and hypoxia, $K_{\mathrm{i}}-67$ and Glut1; (d) overlay image combining markers of epithelial tumor, proliferation, hypoxia, and mitosis: E-cadherin, $K_{\mathrm{i}}-67$, Glut1, and $\mathrm{pHH}$, respectively. Scale bar, $100 \mu \mathrm{m}$.

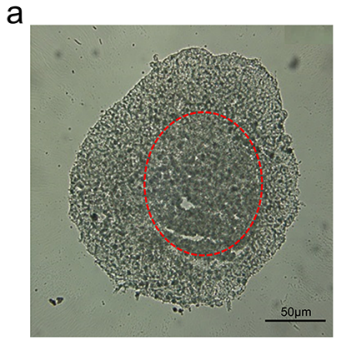

Optical image

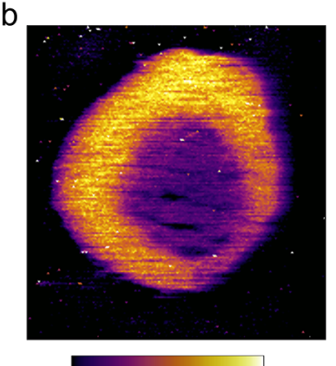

${ }^{24} \mathrm{Mg} \quad{ }_{18 \times 10^{3}}$

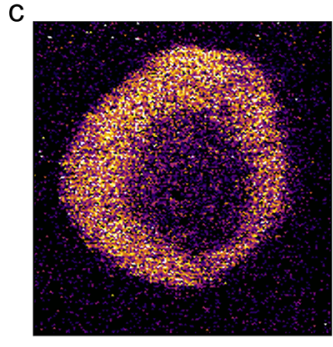

$66 \mathrm{Zn} \quad 250$

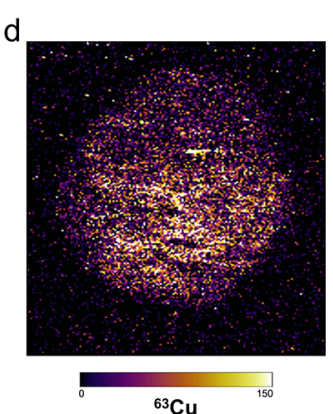

${ }^{63} \mathrm{Cu}$

Figure 7. Elemental distributions within HCC827 aggregoid sections obtained using LA-ICP-MS. (a) Optical image taken before acquisition; necrotic region outlined by red dotted line. Scale bar $50 \mu \mathrm{m}$. Elemental maps of (b) ${ }^{24} \mathrm{Mg}$, (c) ${ }^{66} \mathrm{Zn}$, and (d) ${ }^{63} \mathrm{Cu}$ within the section of aggregoid. 
accumulation of such compounds highlight regions of a proliferative outer zone and a necrotic core, respectively.

\section{CONCLUSION}

We have applied advanced molecular imaging techniques for an in-depth phenotyping of a novel aggregated tumor model. This is the first example of an IMC application with a 3D cell culture model. Combining the IMC data with molecular information from DESI-MSI and LA-ICP-MSI, a detailed characterization of the tumor microenvironment within the aggregoid was possible. Distinct regions of a necrotic core and a proliferative outer was distinguished by each method. The localization of metabolites including lactate, glutamine, and citrate within the aggregoid highlighted the metabolic activity in relation to hypoxia. Mapping the ion density images onto the central biological pathways enabled a clearer understanding of the metabolite behavior within the tumor microenvironment. IMC enabled single-cell phenotyping of protein signaling activity. The protein expression complimented the metabolite data including the expression of the Glut 1 with elevated lactate levels in the core. In addition, the endogenous elemental compositions of $\mathrm{Mg}, \mathrm{Zn}$, and $\mathrm{Cu}$ corresponded to the protein information and further validated the presence of a hypoxia gradient. This study improved our understanding of the molecular activity within a $3 \mathrm{D}$ cell culture tumor microenvironment. Therefore, MSI analysis of tumor aggregoids highlights a potential methodology for in vitro applications of biomedical research and pharmaceutical development.

\section{ASSOCIATED CONTENT}

\section{SI Supporting Information}

The Supporting Information is available free of charge at https://pubs.acs.org/doi/10.1021/acs.analchem.0c02389.

Fluorescent images of $3 \mathrm{D}$ cell culture; table of metabolite assignments, ppm error, and discriminatory analysis; average mean spectra of core, intermediate, and outer regions for metabolite data; and IMC classification and segmentation (PDF)

Video S1, 3D video of aggregoid segmentation (AVI)

Video S2, 3D video of glutamine and GSH distribution within whole aggregoid (AVI)

\section{AUTHOR INFORMATION}

\section{Corresponding Author}

Malcolm R. Clench - Centre for Mass Spectrometry Imaging, Biomolecular Research Centre, Sheffield Hallam University, Sheffield S1 1WB, United Kingdom; (1) orcid.org/0000-00020798-831X; Email: m.r.clench@shu.ac.uk

\section{Authors}

Lucy E. Flint - Centre for Mass Spectrometry Imaging, Biomolecular Research Centre, Sheffield Hallam University, Sheffield S1 1WB, United Kingdom

Gregory Hamm - Imaging and Data Analytics, Clinical Pharmacology and Safety Sciences, BioPharmaceuticals R\&D, AstraZeneca, Cambridge, Cambridgeshire CB4 OWG, United Kingdom

Joseph D. Ready - Centre for Mass Spectrometry Imaging, Biomolecular Research Centre, Sheffield Hallam University, Sheffield S1 1WB, United Kingdom

Stephanie Ling - Imaging and Data Analytics, Clinical Pharmacology and Safety Sciences, BioPharmaceuticals R\&D,
AstraZeneca, Cambridge, Cambridgeshire CB4 OWG, United Kingdom

Catherine J. Duckett - Centre for Mass Spectrometry Imaging, Biomolecular Research Centre, Sheffield Hallam University, Sheffield S1 1WB, United Kingdom

Neil A. Cross - Centre for Mass Spectrometry Imaging, Biomolecular Research Centre, Sheffield Hallam University, Sheffield S1 1WB, United Kingdom

Laura M. Cole - Centre for Mass Spectrometry Imaging, Biomolecular Research Centre, Sheffield Hallam University, Sheffield S1 1WB, United Kingdom

David P. Smith - Centre for Mass Spectrometry Imaging, Biomolecular Research Centre, Sheffield Hallam University, Sheffield S1 1WB, United Kingdom; 이이.org/0000-00015177-8574

Richard J. A. Goodwin - Imaging and Data Analytics, Clinical Pharmacology and Safety Sciences, BioPharmaceuticals R\&D, AstraZeneca, Cambridge, Cambridgeshire CB4 OWG, United Kingdom; Institute of Infection, Immunity and Inflammation, College of Medical, Veterinary and Life Sciences, University of Glasgow, Glasgow G12 8QQ, United Kingdom

Complete contact information is available at: https://pubs.acs.org/10.1021/acs.analchem.0c02389

\section{Author Contributions}

L.E.F. collected the data and wrote the manuscript with feedback from all authors. G.H. contributed to the DESI-MSI analysis. S.L. contributed to the IMC analysis. J.D.R. and C.J.D. assisted with the LA-ICP-MSI analysis. M.R.C., N.A.C., D.P.S., R.J.A.G., and L.M.C. designed the project. All authors have given approval to the final version of the manuscript.

\section{Notes}

The authors declare no competing financial interest.

\section{ACKNOWLEDGMENTS}

Lucy Flint is supported by a Ph.D. studentship sponsored by the Biomolecular Sciences Research Centre, Sheffield Hallam University. AstraZeneca are gratefully acknowledged for the continued support and their collaboration during this project. AstraZeneca would like to acknowledge Cancer Research UK Grand Challenge Consortium for discussions in support of their research. Sheffield Hallam University would like to acknowledge that the aggregated tumour model was originally developed in work supported by National Centre for the Replacement Reduction and Refinement of Animals in Research (NC3Rs) Strategic Imaging Technology for the 3Rs award NC/L001896/1.

\section{REFERENCES}

(1) Swales, J. G.; Hamm, G.; Clench, M. R.; Goodwin, R. J. A. Int. J. Mass Spectrom. 2019, 437, 99-112.

(2) Buchberger, A. R.; DeLaney, K.; Johnson, J.; Li, L. Anal. Chem. 2018, 90, 240-265.

(3) Stoeckli, M.; Chaurand, P.; Hallahan, D. E.; Caprioli, R. M. Nat. Med. 2001, 7, 493-496.

(4) Weaver, E. M.; Hummon, A. B. Adv. Drug Delivery Rev. 2013, 65, 1039-1055.

(5) Takats, Z.; Wiseman, J. M.; Gologan, B.; Cooks, R. G. Science 2004, 306, 471-473.

(6) Chen, H.; Talaty, N. N.; Takáts, Z.; Cooks, R. G. Anal. Chem. 2005, 77, 6915-6927.

(7) Guenther, S.; Muirhead, L. J.; Speller, A. V. M.; Golf, O.; Strittmatter, N.; Ramakrishnan, R.; Goldin, R. D.; Jones, E.; Veselkov, 
K.; Nicholson, J.; Darzi, A.; Takats, Z. Cancer Res. 2015, 75, 18281837.

(8) Pozebon, D.; Scheffler, G. L.; Dressler, V. L.; Nunes, M. A. G. J. Anal. At. Spectrom. 2014, 29, 2204-2228.

(9) Hare, D. J.; New, E. J.; de Jonge, M. D.; McColl, G. Chem. Soc. Rev. 2015, 44, 5941-5958.

(10) Theiner, S.; Schreiber-Brynzak, E.; Jakupec, M. A.; Galanski, M.; Koellensperger, G.; Keppler, B. K. Metallomics. 2016, 8, 398-42.

(11) Theiner, S.; Van Malderen, S. J. M.; Van Acker, T.; Legin, A.; Keppler, B. K.; Vanhaecke, F.; Koellensperger, G. Anal. Chem. 2017, $89,12641-12645$.

(12) Giesen, C.; Wang, H. A O; Schapiro, D.; Zivanovic, N.; Jacobs, A.; Hattendorf, B.; Schuffler, P. J; Grolimund, D.; Buhmann, J. M; Brandt, S.; Varga, Z.; Wild, P. J; Gunther, D.; Bodenmiller, B. Nat. Methods 2014, 11, 417-422.

(13) Chang, Q.; Ornatsky, O. I.; Siddiqui, I.; Loboda, A.; Baranov,

V. I.; Hedley, D. W. Cytometry, Part A 2017, 91, 160-169.

(14) Chang, Q.; Ornatsky, O. I.; Siddiqui, I.; Straus, R.; Baranov, V. I.; Hedley, D. W. Sci. Rep. 2016, 6, 36641.

(15) Chughtai, S.; Chughtai, K.; Cillero-Pastor, B.; Kiss, A.; Agrawal, P.; MacAleese, L.; Heeren, R. M. A. Int. J. Mass Spectrom. 2012, 325$327,150-160$.

(16) Veličković, D.; Chu, R. K.; Carrell, A. A.; Thomas, M.; PašaTolić, L.; Weston, D. J.; Anderton, C. R. Anal. Chem. 2018, 90, 702707.

(17) Yoshii, Y.; Furukawa, T.; Waki, A.; Okuyama, H.; Inoue, M.; Itoh, M.; Zhang, M.; Wakizaka, H.; Sogawa, C.; Kiyono, Y.; Yoshii, H.; Fujibayashi, Y.; Saga, T. Biomaterials 2015, 51, 278-289.

(18) Rimann, M.; Laternser, S.; Gvozdenovic, A.; Muff, R.; Fuchs, B.; Kelm, J. M.; Graf-Hausner, U. J. Biotechnol. 2014, 189, 129-135.

(19) Russo, C.; Lewis, E. E. L.; Flint, L.; Clench, M. R. Proteomics 2018, 18, No. 1700462.

(20) Li, H.; Hummon, A. B. Anal. Chem. 2011, 83, 8794.

(21) Tucker, L. H.; Hamm, G. R.; Sargeant, R. J. E.; Goodwin, R. J. A.; Mackay, C. L.; Campbell, C. J.; Clarke, D. J. Anal. Chem. 2019, 91, 9522-9529.

(22) Liu, X.; Weaver, E. M.; Hummon, A. B. Anal. Chem. 2013, 85, 6295.

(23) Lukowski, J. K.; Weaver, E. M.; Hummon, A. B. Anal. Chem. 2017, 89, 8453-8458.

(24) LaBonia, G. J.; Ludwig, K. R.; Mousseau, C. B.; Hummon, A. B. Anal. Chem. 2018, 90, 1423.

(25) Liu, X.; Lukowski, J. K.; Flinders, C.; Kim, S.; Georgiadis, R. A.; Mumenthaler, S. M.; Hummon, A. B. Anal. Chem. 2018, 90, 1415614164.

(26) Liu, X.; Flinders, C.; Mumenthaler, S. M.; Hummon, A. B. J. Am. Soc. Mass Spectrom. 2018, 29, 516-526.

(27) Palubeckaite, I.; Crooks, L.; Smith, D. P.; Cole, L. M.; Bram, H.; Le Maitre, C.; Clench, M. R.; Cross, N. A. J. Mass Spectrom. 2020, 55, No. e4461.

(28) Swales, J. G.; Dexter, A.; Hamm, G.; Nilsson, A.; Strittmatter, N.; Michopoulos, F.; Hardy, C.; Morentin-Gutierrez, P.; Mellor, M.; Andren, P. E.; Clench, M. R.; Bunch, J.; Critchlow, S. E.; Goodwin, R. J. A. Anal. Chem. 2018, 90, 6051-6058.

(29) Hanahan, D.; Weinberg, R. Cell 2011, 144, 646-674.

(30) Warburg, O. Science 1956, 123, 309-314.

(31) Hayashi, M.; Sakata, M.; Takeda, T.; Yamamoto, T.; Okamoto, Y.; Sawada, K.; Kimura, A.; Minekawa, R.; Tahara, M.; Tasaka, K.; Murata, Y. J. Endocrinol. 2004, 183, 145.

(32) Kim, J.; Tchernyshyov, I.; Semenza, G. L.; Dang, C. V. Cell Metab. 2006, 3, 177-185.

(33) Cui, X.; Han, Z.; He, S.; Wu, X.; Chen, T.; Shao, C.; Chen, D.; Su, N.; Chen, Y.; Wang, T.; Wang, J.; Song, D.; Yan, W.; Yang, X.; Liu, T.; Wei, H.; Xiao, J. Oncotarget. 2017, 8, 24840-24852.

(34) Fan, J.; Kamphorst, J. J.; Mathew, R.; Chung, M. K.; White, E.; Shlomi, T.; Rabinowitz, J. D. Mol. Syst. Biol. 2013, 9, 712.

(35) Martínez-Reyes, I.; Chandel, N. S. Nat. Commun. 2020, 11, $102-111$.
(36) Curcio, E.; Salerno, S.; Barbieri, G.; De Bartolo, L.; Drioli, E.; Bader, A. Biomaterials 2007, 28, 5487-5497.

(37) Grimes, D. R.; Kelly, C.; Bloch, K.; Partridge, M. J. R. Soc., Interface 2014, 11, 20131124.

(38) Däster, S.; Amatruda, N.; Calabrese, D.; Ivanek, R.; Turrini, E.; Droeser, R. A.; Zajac, P.; Fimognari, C.; Spagnoli, G. C.; Iezzi, G.; Mele, V.; Muraro, M. G. Oncotarget. 2017, 8, 1725-1736.

(39) Beloribi-Djefaflia, S.; Vasseur, S.; Guillaumond, F. Oncogenesis 2016, 5, No. e189.

(40) Armstrong, J. S.; Steinauer, K. K.; Hornung, B.; Irish, J. M.; Lecane, P.; Birrell, G. W.; Peehl, D. M.; Knox, S. J. Cell Death Differ. 2002, 9, 252-263.

(41) Kipp, A. P.; Deubel, S.; Arnér, E. S. J.; Johansson, K. Redox Biol. 2017, 12, 403-409.

(42) Downward, J. Nature 2001, 411, 759-762.

(43) Hoffman, M. D.; Sniatynski, M. J.; Kast, J. Anal. Chim. Acta 2008, 627, 50-61.

(44) Simiantonaki, N.; Kurzik-Dumke, U.; Karyofylli, G.; Jayasinghe, C.; Kirkpatrick, C. Int. J. Oncol. 2007, 31, 269-275.

(45) Lamouille, S.; Xu, J.; Derynck, R. Nat. Rev. Mol. Cell Biol. 2014, $15,178-196$

(46) Essid, N.; Chambard, J. C.; Elgaaïed, A. B. Bosnian J. Basic Med. Sci. 2018, 18, 336-346.

(47) Lehmann, S.; te Boekhorst, V.; Odenthal, J.; Bianchi, R.; van Helvert, S.; Ikenberg, K.; Ilina, O.; Stoma, S.; Xandry, J.; Jiang, L.; Grenman, R.; Rudin, M.; Friedl, P. Curr. Biol. 2017, 27, 392-400.

(48) Wang, Z.; Wei, Q.; Han, L.; Cao, K.; Lan, T.; Xu, Z.; Wang, Y.; Gao, Y.; Xue, J.; Shan, F.; Feng, J.; Xie, X. J. Cell. Mol. Med. 2018, 22, 429-438.

(49) Takahashi, Y.; Sawada, G.; Kurashige, J.; Matsumura, T.; Uchi, R.; Ueo, H.; Ishibashi, M.; Takano, Y.; Akiyoshi, S.; Iwaya, T.; Eguchi, H.; Sudo, T.; Sugimachi, K.; Yamamoto, H.; Doki, Y.; Mori, M.; Mimori, K. Anticancer Res. 2013, 33, 1927-1934.

(50) Kim, J.; Jeong, H. S.; Chung, T.; Kim, M.; Lee, J. H.; Jung, W. H.; Koo, J. S. Oncotarget. 2017, 8, 65064-65076.

(51) Ouiddir, A.; Planes, C.; Fernandes, I.; VanHesse, A.; Clerici, C. Am. J. Respir. Cell Mol. Biol. 1999, 21, 710-718.

(52) Schneider, A.; Younis, R. H.; Gutkind, J. S. Neoplasia. 2008, 10, 1295-1302.

(53) Rogakou, E. P.; Nieves-Neira, W.; Boon, C.; Pommier, Y.; Bonner, W. M. J. Biol. Chem. 2000, 275, 9390-9395.

(54) Tanaka, T.; Halicka, H. D.; Huang, X.; Traganos, F.; Darzynkiewicz, Z. Cell Cycle 2006, 5, 1940-1945.

(55) Vernon, W. B. Magnesium 1988, 7, 234-248.

(56) MacDonald, R. S. J. Nutr. 2000, 130, 1500S-1508S.

(57) Walker, G. M. Magnesium 1986, 5, 9-23.

(58) Nardinocchi, L.; Puca, R.; Givol, D.; D’Orazi, G. Cell Cycle 2010, 9, 1270-1275.

(59) Wu, Z.; Zhang, W.; Kang, Y. J. Metallomics. 2019, 11, 429-438.

(60) Feng, W.; Ye, F.; Xue, W.; Zhou, Z.; Kang, Y. J. Mol. Pharmacol. 2009, 75, 174-182.

(61) Sowter, H. M.; Ratcliffe, P. J.; Watson, P.; Greenberg, A. H.; Harris, A. L. Cancer Res. 2001, 61, 6669-6673.

(62) Büchler, P.; Reber, H. A.; Büchler, M.; Shrinkante, S.; Büchler, M. W.; Friess, H.; Semenza, G. L.; Hines, O. J. Pancreas 2003, 26, $56-64$.

(63) Zimnicka, A. M.; Tang, H.; Guo, Q.; Kuhr, F. K.; Oh, M.; Wan, J.; Chen, J.; Smith, K. A.; Fraidenburg, D. R.; Choudhury, M. S. R.; Levitan, I.; Machado, R. F.; Kaplan, J. H.; Yuan, J. X. PLoS One 2014, 9, No. e90544.

(64) O’Neill, E. S.; Kaur, A.; Bishop, D. P.; Shishmarev, D.; Kuchel, P. W.; Grieve, S. M.; Figtree, G. A.; Renfrew, A. K.; Bonnitcha, P. D.; New, E. J. Inorg. Chem. 2017, 56, 9860-9868.

(65) Zhang, J. Z.; Bryce, N. S.; Siegele, R.; Carter, E. A.; Paterson, D.; de Jonge, M. D.; Howard, D. L.; Ryan, C. G.; Hambley, T. W. Integr. Biol. (Camb). 2012, 4, 1072-1080. 